\title{
Choice? Making health care decisions in the United States and Canada
}

\author{
Joseph S. Ross, MD, MHS ${ }^{*}$ and Allan S. Detsky, MD, PhD ${ }^{\dagger}$ \\ * Departments of Geriatrics and Adult Development and Medicine, Mount Sinai School of Medicine, \\ New York, NY, USA and HSR\&D Research Enhancement Award Program and Geriatrics Research, \\ Education, and Clinical Center, James J. Peters Veterans Administration Medical Center, Bronx, \\ NY, USA \\ † Department of Medicine, Mount Sinai Hospital and University Health Network and Departments \\ of Health Policy, Management, and Evaluation, and Medicine, University of Toronto, Toronto, \\ Ontario, Canada
}

\begin{abstract}
Media speculation about the scope of proposals for health care reform in the United States have led many Americans to be "very concerned" that changes will limit their choices in the future (ABC news poll 6/24/09). Health care choices are made on three levels: insurance plans, sources of care (physicians and hospitals), and clinical decisions (diagnostic tests and treatments). In this Commentary, we discuss the extent to which Americans currently are able to exercise choices. For context, we will compare the U.S. environment with that in Canada, partly because its health system, with much greater government involvement, is often publicly-portrayed in the U.S. as limiting choice.
\end{abstract}

\section{Insurance Coverage}

\section{United States}

All American citizens, other than those 65 years and older and the very poor, make the choice to purchase private health insurance (or not). Nearly 47 million people have no coverage. It is unknown how many chose not to purchase coverage, cannot afford coverage, or cannot obtain overage. Uninsured people are severely limited in all other health care choices. They must either receive charity care or pay for care out of pocket, possibly incurring substantial debt or bankruptcy.

The choice of insurance plan is also often limited; 96\% of U.S. Metropolitan Statistical Areas have insurance markets that are highly concentrated, consolidated among only a few companies. ${ }^{1,2}$ Employers who offer health insurance also frequently limit choices. One plan is often established as preferred and made less expensive through lower premiums and copayments. Few working adults can afford to purchase plans outside of their employer because their costs (and risks) are neither subsidized nor pooled. In addition, loss or change of jobs often results in lost coverage or substantially higher payments to retain existing coverage.

Corresponding Author: Allan S. Detsky, MD, PhD, Mount Sinai Hospital, 429-600 University Avenue, Toronto, Ontario, M5G 1X5, CANADA; (p) 416-586-8507; (f) 416-586-8350; adetsky@ mtsinai.on.ca.

Financial Disclosures: None reported.

Disclaimer: The views expressed in this article are those of the authors and do not necessarily represent the views of the US Department of Veterans Affairs. 
In contrast, insurers have the choice to accept or deny people coverage for innumerable reasons, often related to prior or current medical conditions. They may even deny coverage among those they insure for specific care related to pre-existing conditions.

\section{Canada}

All Canadian citizens and landed immigrants are eligible to receive health insurance through the one government-sponsored plan administered by their province or territory. Because the application process is simple, without screening for current or pre-existing health conditions or means-testing, un-enrolled individuals who seek care are routinely enrolled on sight by physicians and hospitals, prohibiting any need for charity care. Insurance coverage is not tied to employment and so does not change if there is loss or change of jobs.

The Canadian government mandates that all provincial plans cover "necessary care", including most physician and hospital services. However, there are private insurance plans to obtain coverage for services that are not covered by some provincial plans, such as pharmaceuticals, private rooms in hospitals, dental care, home care, physiotherapy, and chiropractic care.

\section{Hospitals and Physicians}

\section{United States}

The choice of hospital or physician is often made by an individual's of insurance plan. Whether structured as a health maintenance organization (HMO), preferred provider organization (PPO), or otherwise, most plans attempt to limit costs by designating hospitals and physicians, offering either discounted coinsurance or additional benefits to promote their use. "Going outof-network" requires that individuals pay substantially larger co-payments.

Health insurance plans often require individuals to choose a primary care physician upon enrollment who arranges referrals to specialist physicians. $40 \%$ of Americans report difficulties seeing a specialist; $40 \%$ because of long waiting times, $31 \%$ because of a denied referral or waiting for a referral, and $17 \%$ because they cannot afford private insurance. ${ }^{3}$

Choice is also influenced by availability of care. The U.S. ranks last in international comparisons for patients finding it somewhat or very difficult to get care on nights or weekends without going to an Emergency Department. ${ }^{4}$

\section{Canada}

Canadians may choose to receive care from any physician or hospital, anywhere in Canada. Typically, a family physician provides primary care and makes referrals to specialists. There is no limit to the number of different physicians a patient can see. If they are not satisfied with the care of one physician or hospital, they may change to another. Specialists generally require a referral from another physician (not necessarily the family physician) to be reimbursed for a "consultation", but can evaluate any patient and be reimbursed for an "assessment". Individuals may present to any hospital emergency room and request specialty care, which is scheduled so long as the emergency physician, who has no incentive not to, agrees.

\section{Diagnostic Testing and Treatments}

\section{United States}

The common presumption is that there is access to every new diagnostic test, procedure, medication and intervention in the U.S. However, insurance plans make use of formularies that restrict medications. Generally, at least one medication in any pharmacologic class is offered among "first tier" medications, for which co-payments are the least expensive. Choosing 
cheaper or generic medications is also facilitated by requiring prior authorization for brand name medications when a generic alternative exists or by offering one medication in a class at a lower co-payment after contracting with the manufacturer to obtain a discounted price.

Similarly, although many routine, less expensive services are not restricted, prior authorization is often used to limit the use of expensive health care services such as Magnetic Resonance Imaging (MRI) or experimental medications.

In international comparisons, U.S. waiting times are consistently shorter for elective surgeries and procedures. ${ }^{5}$ However, while physicians and hospitals generally are able and willing to provide care quickly and efficiently, insurance plans are not necessarily similarly willing to fully reimburse charges. Often, it is not until after the procedure and utilization review, that individuals become aware of the substantial portion of the payment they must incur. Individuals who cannot afford care, of whom there are many in the U.S., ${ }^{4}$ have no waiting times; they rarely receive care.

\section{Canada}

Virtually all health care services available in the United States are also available in Canada. There is regionalization of specialized services, such as surgical, oncology or imaging procedures. For services unavailable in all parts of Canada, such as gamma knife surgery, governments will reimburse care received in the U.S., but patients are required to apply in advance. For care in Canada, there is no utilization review and all services are covered in full without co-payment. Physicians and hospitals are paid quickly by government. Patients receive no bill and fill out no forms. However, as opposed to prior authorization, the use of expensive health care services is limited by supply; there are fewer facilities per capita that provide this care. Provincial and private drug plans do use formularies similar to the U.S.

"Waiting times" is less a health care issue than a political one. Both federal and provincial governments have responded to media-facilitated public pressure to reduce wait times for specific services, such as hip and knee replacement, cataract surgery, cancer surgery and ED care through strategies that resemble pay-for-performance. ${ }^{7,8}$ Moreover, there is provincial variation in reliance on private facilities that charge individuals directly for common diagnostic services (e.g. blood drawing, imaging); some provinces have allowed (or tacitly encouraged) these facilities, allowing patients to choose to pay for some routine care to receive it sooner.

\section{The Bottom Line}

Government-sponsored plans, like Canada's, are frequently publicly-portrayed as limiting choice. However, there is clear evidence that for Canada's health care system, less choice in insurance coverage (although guaranteed), has not resulted in less choice of hospitals, physicians, and diagnostic testing and treatments compared to the U.S. In fact, there is arguably more.

\section{Acknowledgments}

Funding/Support: Dr. Ross is currently supported by the National Institute on Aging (K08 AG032886) and by the American Federation of Aging Research through the Paul B. Beeson Career Development Award Program.

Role of the Sponsor: The funding organizations had no role in the preparation, review, or approval of the manuscript.

\section{References}

1. American Medical Association. Competition in Health Insurance: A comprehensive study of U.S. markets. [Accessed August 13, 2009]. A 2007 update. 2007; http://www.ama-assn.org/ama1/pub/upload/mm/368/compstudy_52006.pdf 
2. Biles, B.; Pozen, J.; Guterman, S. Paying Medicare Advantage by Competitive Bidding: How Much Competition Is There? 2009 [Accessed August 13, 2009].

http://www.commonwealthfund.org/ /media/Files/Publications/Issue\%20Brief/2009/Aug/

1311_Biles_paying_Medicare_Advantage_plans_competitive_bidding.pdf

3. Blendon RJ, Schoen C, DesRoches C, Osborn R, Zapert K. Common concerns amid diverse systems: health care experiences in five countries. Health Aff (Millwood) May-Jun;2003 22(3):106-121. [PubMed: 12757276]

4. Davis, K.; Schoen, C.; Schoenbaum, SC., et al. Mirror, mirror on the wall: an international update on the comparative performance of American health care. New York, NY: The Commonwealth Fund; May. 2007

5. Blendon RJ, Schoen C, DesRoches CM, Osborn R, Zapert K, Raleigh E. Confronting competing demands to improve quality: a five-country hospital survey. Health Aff (Millwood) May-Jun;2004 23(3):119-135. [PubMed: 15160810]

6. Katy SJ, Cardiff K, Pascali M, Baren ML, Evans RG. Phantoms in the Snow “Canadians” Use of Health Care Services in the United States Health Affairs (Millwood) 2002 May-June;21(3):19-31.

7. Media Releases Canada's New Government announces Patient Wait Times Guarantees Office of the Prime Minister. Apr 42007 [accessed September 1, 2009].

8. Tam, Pauline. Key Surgical Wait Times Dropping Fast; Cataract surgery, joint replacements speedier but still behind provincial targets. The Ottawa Citizen; Ottawa, Ontario: Nov 26. 2008 p. C1 